\title{
The implication of irrational thinking in suicidal risk for depressed
} and non-depressed population

\author{
Mihai Marian*1, Gabriel Roseanu루, Ioana Mihaela Tomulescu² and Claudia \\ Teodora Pusta ${ }^{3}$
}

Address: ${ }^{1}$ Department of Psychology, Faculty of Social and Humans Sciences, University of Oradea, Oradea, Romania, ${ }^{2}$ Department of Biology, Faculty of Sciences, University of Oradea, Oradea, Romania and ${ }^{3}$ Department of Anatomy, Faculty of Medicine and Pharmacy, University of Oradea, Oradea, Romania

* Corresponding author

from International Society on Brain and Behaviour: 3rd International Congress on Brain and Behaviour

Thessaloniki, Greece. 28 November - 2 December 2007

Published: 17 April 2008

Annals of General Psychiatry 2008, 7(Suppl I):S270 doi:I0.1 I86/I744-859X-7-SI-S270

This abstract is available from: http://www.annals-general-psychiatry.com/content/7/SI/S270

(c) 2008 Marian et al.; licensee BioMed Central Ltd.

\section{Background}

In this paper we studied the influence of Ellis's irrational beliefs (awfulizing, "must", self downing and low frustration tolerance) on suicidal risk. From a cognitive point of view the most important factor in suicide is the way in which people view their life experiences. Ellis suggests that unrealistic demands from the world and self are a key factor in suicide ideation.

\section{Materials and methods}

A sample of 156 subjects (males and females) was used. This sample was divided into two sub-samples, one composed of depressed subjects, and another composed of non-depressed subjects. The Attitudes and Believes scale II was used to assess the subjects' level of irrational thinking and the Beck Hopelessness Scale was used to measure suicidal risk.

\section{Results}

The obtained results support the idea that irrational believes (awfullizing, "must", self downing and low frustration tolerance) are crucial factors in suicidal ideation and behavior for both non-depressed and depressed subjects.

\section{Conclusions}

It seems that awfulizing and "must" are factors that are more important for the non-depressed population and that a high level of low frustration tolerance is a very good predictor of suicidal ideation. 